Article

\title{
Business Management Teaching-Learning Processes in Times of Pandemic: Flipped Classroom at A Distance
}

\author{
Julen Izagirre-Olaizola ${ }^{1,2, *(1)}$ and Jon Morandeira-Arca ${ }^{1,2}$ \\ 1 Department of Financial Economics II, Faculty of Economics and Business (Gipuzkoa), University of the \\ Basque Country (UPV/EHU), 20018 Donostia, Basque Country, Spain; jon.morandeira@ehu.eus \\ 2 GEZKI, Institute of Cooperative Law and Social Economy, Elhuyar 2, 20018 Donostia, Basque Country, Spain \\ * Correspondence: julen.izaguirre@ehu.eus
}

Received: 12 November 2020; Accepted: 2 December 2020; Published: 4 December 2020

check for updates

\begin{abstract}
The main objective of this study is to present a teaching-learning experience carried out before the appearance of the COVID-19 pandemic and to analyze its usefulness in times of social and academic restrictions, as well as its fit into an online teaching format. In recent years, much research has been done on the development and application of new teaching methodologies, but the current health emergency situation means that it is necessary to assess how these methodologies are useful in a context of social distancing. Managing teaching-learning processes following the closure of educational centers due to the pandemic caused by COVID-19 presents a significant challenge, not just in Business Management, but across all subjects. In the context of a pandemic, active methodologies take on greater importance as a way of adapting to new, socially distanced educational needs. This article presents a study carried out among students of Business Management at the University of the Basque Country (Spain). The study focuses on the context of the flipped classroom methodology, with students being asked to rate the effectiveness of this methodology, before and after the pandemic. Following the appearance of the pandemic, opinions have been strengthened in favor of the inverted classroom methodology, which is shown to be a powerful methodological alternative compatible with online teaching. Educational authorities must strengthen the technological tools as well as the teacher skills needed to develop capacities related to the rapid response to current and future teaching challenges.
\end{abstract}

Keywords: COVID-19; flipped classroom; active methodologies; university students

\section{Introduction}

The World Health Organization (WHO) classified COVID-19 as a global pandemic in March 2020 [1]. To prevent its spread, many countries followed strict protocols, such as the total closure of facilities or social distancing, while a few countries preferred to count on group immunity [2]. Efforts to stop the viral outbreak included telecommuting, offering flexible working hours, and closing institutions that were at risk of contagion. Many governments concluded that social isolation was a way of containing the spread of the disease, based on the premise that isolation would help prevent the collapse of the health system and guarantee that medical and hospital care was available for the most critically ill cases [3]. This closure of shared spaces naturally affected schools, universities, and many other educational institutions. This situation forced all levels of educational institutions to operate remotely, with little warning, and consider ways of implementing distance learning [4].

Given that many teachers, as well as students, had little or no experience of online teaching-learning, the process of operating remotely brought with it many challenges [5]. A change was required, 
overnight, in the way in which business administration teaching was delivered (and other disciplines), with teachers needing to adopt a facilitator role and to become more familiar with digital technologies, the only means of imparting the theoretical component of the curricula [6].

With the aim of identifying useful tools for potentially similar situations in the future, this article proposes the application of active methodologies, specifically the flipped classroom or inverted classroom approach, to organize the teaching-learning process in the field of study of Business Economics.

Active learning formulas are based on the completion of tasks by students so that their assimilation of the subject is done in the most autonomous way possible. Consequently, learning and behavioral patterns of students can be established based on the development of their abilities as an individual belonging to a group [7]. This search for autonomy is clearly a value that has grown in importance in the context of isolation and limited attendance brought about by COVID-19.

The transition from an educational model based on teaching to a model based on learning requires a profound cultural transformation within universities. Methodological innovation is one of the cornerstones of this revolution. In the case of Spanish universities (as well as in other contexts), the renovation of educational methodologies is perceived as "a process that is essential to update the educational offer of Spanish universities, and which in fact is already underway in some way, which does not prevent it from still arousing a number of uncertainties" [8]. This transformation of the education system is the response needed to meet two significant demands: The need to adapt to a global world and the evolution of a knowledge society [9]. Today, a third demand has been added, the need to adapt to a global pandemic context $[10,11]$. In fact, the emergence of new technologies has already introduced novel approaches to education: New training modalities (such as e-learning and blended learning) and mass education (such as mass and open online courses-MOOC); new ways for collaborative learning among students (WebQuest, project-based learning); improvement in the acquisition of skills with access to large amounts of information; changes in the roles of teachers and students; methodological changes (flipped classroom), etc., [12].

The study described in this article is related to the proposed application of flipped classroom methodologies in a non-classroom or blended environment. The main objective of this work is, on the one hand, to present a teaching-learning experience carried out before the appearance of the COVID-19 pandemic and, on the other hand, to analyze its usefulness in times of social and academic restrictions, as well as its fit into an online teaching format.

The study was carried out among students of the Business Administration and Management Degree course of the University of the Basque Country (UPV/EHU). The fieldwork carried out consisted of two phases. In the first phase, the flipped classroom methodology was applied in subjects related to business administration between October and December 2019, before the appearance of the COVID-19 pandemic. Information was collected from the students about the advantages and disadvantages of applying these methodologies. In a second phase, the fieldwork was supplemented by asking the same students about the effectiveness of using these methodologies in a pandemic context.

The flipped classroom application was carried out with the support of the Socrative tool, which has been shown to be very useful for improving the efficiency of active and collaborative learning and to be a good fit in the context of social isolation. In addition, the use of case studies to cover course content works well in the flipped classroom context. The use of case studies is a teaching-learning tool with a long tradition in the field of Business Economics, and perfectly complementary within the framework of the implementation of active methodologies.

The findings of this paper serve to show the appropriateness of this methodology in a global pandemic context. Policy makers in public and private educational institutions, with particular emphasis on higher education, should seek to strengthen the application of methodologies that are compatible with emergency and distance learning situations. To this end, both the development of appropriate technological tools and a commitment to train teachers in methodology and adaptive skills can be of particular importance. 


\section{Methodological Context and Tools}

\subsection{Flipped Classroom as an Active Learning Methodology}

As a consequence of the whole transformation process described in the introduction and in the implementation of a distance or blended learning context, the emphasis is on what the students do rather than what the teachers say. It is, therefore, vitally important to develop active learning methodologies and a flexible approach to time management. As its name suggests, active methodologies are based on making students participate during their learning process [13]. Felder and Brent offered a more restrictive definition, but perhaps a more useful one: "Active learning consists of short course-related individual or small-group activities that all students in a class are called upon to do, alternating with instructor-led intervals in which student responses are processed and new information is presented" [14].

It seeks to promote a more participative attitude among students, turning them into active agents of their own education [15]. The underlying idea is to develop ways of increasing the motivation and involvement of students at all stages of education, including university [16]. A flipped classroom is one of these ways.

A flipped classroom is a pedagogical approach in which direct instruction is transferred from the collective learning space to the individual learning space so that the resulting group space is transformed into a dynamic and interactive environment in which the teacher guides the students by introducing them to concepts and developing their creativity in the subject matter being studied [17].

It consists of using time outside the classroom to carry out certain learning processes that were traditionally done within the classroom and then, as a group (in this case, in the virtual classroom), the teacher focuses on facilitating and enhancing the learning process through applying the knowledge and concepts in a creative way [18].

The potential of this teaching methodology lies in the fact that the time invested in explaining the subject, for example through lectures, is designated as work that the students can do quietly at home by way of video recordings, a narrated presentation, texts, writings, etc., [7,19]. This approach, gaining in popularity, has seen its value grow in the context of forced social distancing.

In other words, from the perspective of the flipped classroom, the master classes give way to collective spaces, responding to the individual needs of the students in order to obtain higher levels of commitment, and reinforcing active learning without sacrificing content. Thus, teachers spend more time applying knowledge and integrating it through learning strategies, promoting interaction in the classroom, guaranteeing higher levels of understanding, and reinforcing content. In other words, tasks with a high cognitive level (problem solving, case analysis, or project development) are carried out in the classroom, while those with a lower cognitive level (reading, listening, observing) are carried out outside of the classroom space $[20,21]$.

This approach is intended to develop the autonomy of the students, turning them into active managers of their learning process rather than just receivers of instructions. The students, therefore, control their own learning, becoming more involved in the process, which reinforces their autonomy. Roach [22] suggested that there was a significant increase in the active participation of students after using flipped classroom methodologies, with positive reactions about the experience. All this entails a profound transformation both for students and teachers, who must leave their comfort zone to find another way of teaching and learning. Teachers willing to change their methodology will suffer doubts and have concerns over the apparent lack of control, but they will have to adapt and internalize new strategies and tools to have more and better resources that can help them to function in a more uncertain and demanding context.

Flipped Learning Network Hub is a community that offers resources related to this methodology. This body establishes the four pillars that make up flipped learning, as shown in Table 1. 
Table 1. The four pillars of the inverted classroom (flipped learning).

\begin{tabular}{|c|c|c|}
\hline Pillar FLIP & Content & Teaching Role \\
\hline Flexible environment & $\begin{array}{l}\text { Flipped learning offers various learning modes. } \\
\text { Flexible spaces should be provided for students to } \\
\text { decide where and when to learn. } \\
\text { The teacher is flexible in terms of expectations and } \\
\text { pace of learning. }\end{array}$ & $\begin{array}{c}\text { F1: Space for interaction and reflection } \\
\text { F2: Continuous assessment } \\
\text { F3: Facilitate learning and } \\
\text { performance pathways }\end{array}$ \\
\hline Learning culture & $\begin{array}{l}\text { Learning-centred approach (the teacher is not the } \\
\text { primary source of information). } \\
\text { Group space for consolidating and } \\
\text { enriching learning. } \\
\text { Students active in adding to their own knowledge. }\end{array}$ & $\begin{array}{l}\text { L1: Opportunities to develop } \\
\text { autonomous learning activities } \\
\text { L2: Accessible and differentiated } \\
\text { activities that provide learning } \\
\text { through feedback }\end{array}$ \\
\hline Intentional content & $\begin{array}{l}\text { Teachers think about how to help students } \\
\text { understand concepts. } \\
\text { Teachers determine what students need to learn } \\
\text { and what materials to explore on their own. } \\
\text { Optimization of class time to develop active } \\
\text { learning strategies. }\end{array}$ & $\begin{array}{l}\text { I1: Prioritization of concepts so that they } \\
\text { are accessed by students on their own } \\
\text { I2: Creation of relevant content } \\
\text { I3: Differentiated, accessible and } \\
\text { relevant content for all students }\end{array}$ \\
\hline Professional educator & $\begin{array}{l}\text { The role of the teacher is even more important than } \\
\text { in the traditional methodology. Continuous } \\
\text { observation, relevant feedback } \\
\text { Reflective teaching practices, connected and open } \\
\text { to criticism and improvement. } \\
\text { Tolerance to controlled chaos in the classroom. }\end{array}$ & $\begin{array}{l}\text { P1: Flexible and customized availability } \\
\text { P2: Continuous formative evaluation } \\
\text { P3: Collaboration and reflection with } \\
\text { other teachers for the transformation of } \\
\text { teaching practice }\end{array}$ \\
\hline
\end{tabular}

Source: [23].

Both in the traditional model (the teacher dictates, and the students listen and take notes trying to understand/learn what is explained to them) and in the flipped classroom model, students must externalize their knowledge in order to be assessed. In traditional teaching, students are expected to understand everything straight away, although they do not really have time to reflect on what is being said and it is easy to miss important issues [21].

However, the evaluation in flipped classes is more objective and precise since the teacher has more data to carry out a student assessment as they have more time in class to check the capacities and competences of the students [18].

\subsection{The Web 2.0 Environment in the Context of Teaching-Learning in the Inverted Classroom: The Socrative Tool}

The so-called Student Response Systems (SRS) require no additional investment as they are compatible with the personal digital devices that all students have, such as a smartphone. The integration of the smartphone in learning has many advantages, some of which are: The potential to develop independent and collaborative learning; the removal of barriers related to formality in learning; the ability to attract and focus student attention; the acquisition by students of a knowledge base prior to a lesson; greater flexibility, accessibility; an increase in self-esteem; and better interaction between teacher and student $[24,25]$. Clearly, the flexibility afforded to a student in being able to continue their studies by using their own digital device is invaluable in the context of a pandemic, such as that of COVID-19.

There is a range of 2.0 interfaces available that allow the applied development of methodologies like those described above, such as Edmodo, Edcanvas/Blendspace, Go Soapbox, Kahoot, Poll Everywhere, or Screencast $[20,26,27]$. However, for our study, we choose to use the Socrative interface, one of the more popular tools and that also allows free access to a large part of its functionalities.

According to a study by Wash [27], Socrative seems to be the tool that offers greater flexibility and ease of implementation, and its use seems to enhance higher participation rates and allows for immediate feedback.

The Socrative interface (and mobile application) provides students and teachers with a tool for evaluating the teaching-learning process from a computer, tablet, Smartphone, or mobile phone. Thanks to the possibility of viewing answers and results instantly, as soon as the teacher poses a 
question, he/she can assess the level of understanding of the group as well as identify the needs of the students.

The teacher must open an account and then create a virtual classroom. Students can download the application or connect directly through the website without the need for downloads. They can enter the classroom through a code using their own device (a mobile phone is the simplest and most flexible option).

The interface offers a wide variety of options, such as instant grading, generating and displaying graphs of the answers, or the design of various types of questions. Contests, games, etc., are also offered through this interface. In this way, feedback between teachers and students is reinforced, and an individualized report can even be created to meet the need of each student.

\section{Phases Implemented in the Teaching-Learning Experience}

The development of the activity was configured through the different phases that we detail below (Figure 1).

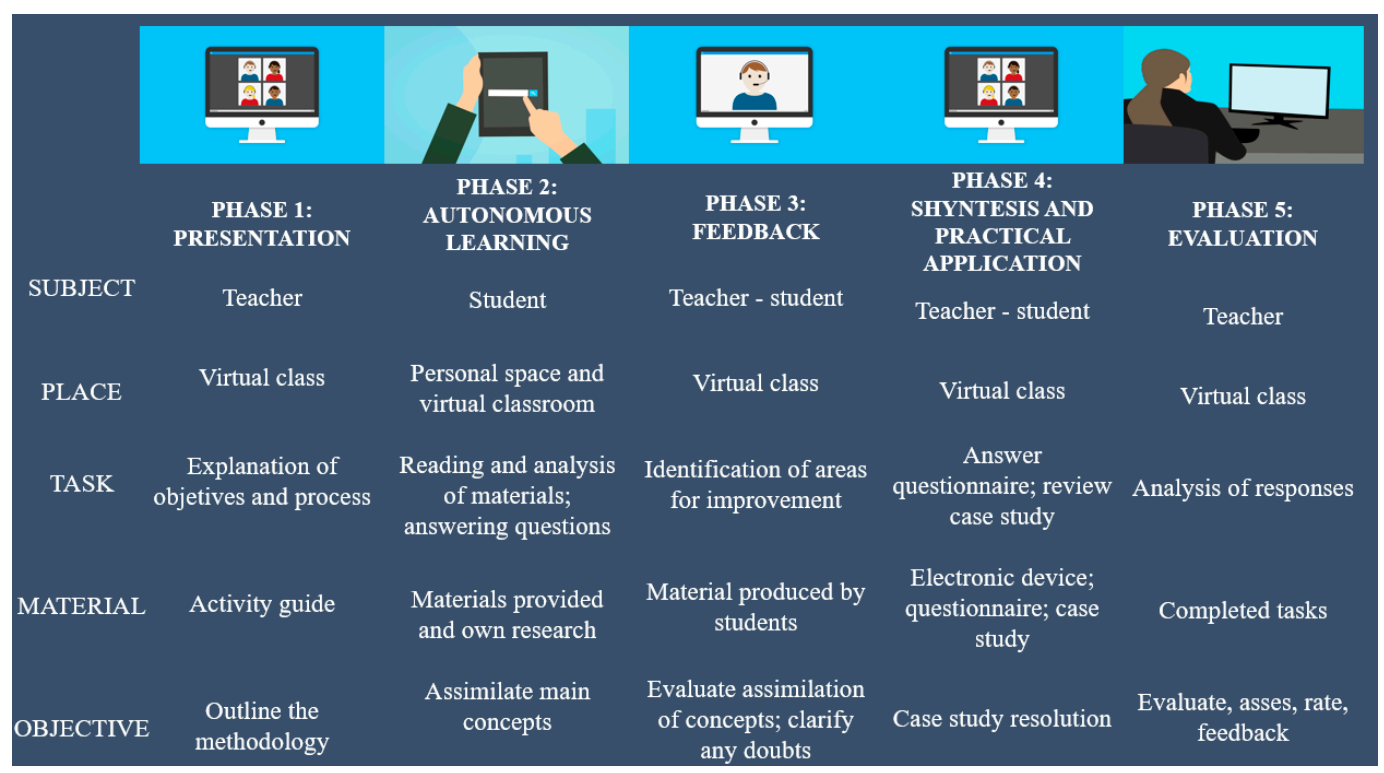

Figure 1. Phases of the flipped classroom methodology in a virtual environment. Source: Compiled by Table authors. Presentation Phase.

The week before the activity was carried out, the objective of the activity was explained to the students, indicating the expected competences or learning outcomes. The process was explained in detail, indicating exactly what individual tasks needed to be carried out, the approximate time that students should invest in each task, the deadlines for completion and the subsequent activity in the classroom, together with the implications in terms of continuous evaluation and assessment. In our case, this task was not used as part of the final grade, although it could be used if deemed necessary. It may be useful to make a synthetic guide of the activity in which all these elements are collected.

\subsection{Self-Learning Phase Outside the Classroom}

The active learning of the students is carried out in two phases. The first one consists of reading the basic and complementary material of the subject matter (a case study to be solved later in class) prepared by the teaching staff of the subject, available in the virtual classroom. In this didactic unit, the main concepts that need to be understood for the development of the specific competences of the subject are addressed. Alternatively, other teaching materials such as existing book chapters, scholarly articles, or videos could be used. 
Once the material has been read, and prior to the development of the activity in the classroom, it is essential to check that the reading task has been carried out by the students. In our case, the students had to answer a questionnaire through the virtual classroom with questions related to the main concepts that should have been assimilated through reading. They were also asked if there was a concept they did not understand or if they needed a more detailed explanation of a topic.

\subsection{Feedback Phase}

The feedback phase is the one with the greatest added value, both for students and teachers. This feedback occurs in two ways:

(i) From teachers to students, individually and collectively: Before class, teachers analyze individual responses in the virtual classroom. In the event that the teacher identifies any concepts that have not been correctly understood in a generalized way, a collective feedback session is carried out in the classroom, which is complemented, if necessary, with individualized reinforcement.

(ii) From students to teachers: This first analysis of the responses tells us the degree of assimilation of the concepts and identifies the aspects that have proved more difficult to understand. Likewise, the open question addressed to the students also tends to show those concepts or parts of the didactic unit that deserve additional explanation or clarification in the classroom. This feedback is the basis of the continuous improvement that underlies the active methodologies, giving rise to the modification and improvement of the materials and teaching/learning strategies used.

\subsection{Synthesis Phase and Practical Application in the Classroom}

Once students have completed the autonomous learning phase, their learning continues in the classroom by way of different tasks. In the experience set up in 2019, this phase was carried out in person. In the event of there being a situation of isolation, with face-to-face classes suspended, this phase could be carried out remotely, either through specific tools that the university itself uses (based on Moodle, for example), or using other type of tools, such as those described in Section 2.2.

The first step involves students using the Socrative platform (described in the previous section) via mobile devices to individually answer a set of multiple-choice questions. This application offers a wide variety of formats, both for questions and for feedback. In our case, we choose the multiple-choice questionnaire with immediate feedback, both for the students and for the group as a whole, allowing more detailed explanations to be given in response to incorrect answers or any lack of understanding. At the end of the activity, the students know the number of correct answers they have obtained, and the teachers perceive the degree of assimilation of the subject studied, which allows them to emphasize those aspects that need additional explanation or more face-to-face work.

In the next step, the classroom activity (face-to-face or virtual) is completed with two practical application exercises based on the resolution of cases presented by the teaching staff. The aim of this activity is for students to apply the knowledge they acquired on the subject to a real, practical case, by completing higher-level cognitive tasks such as identifying, classifying, evaluating, assessing, deciding, or solving [28,29]. The first practical case is carried out in a group way, to develop transversal competences related to teamwork, while the second is solved individually to deepen autonomous study and self-learning.

\subsection{Activity Evaluation Phase}

The process ends with the necessary evaluation of the activity, aimed at gathering the perspectives and expectations of the students in relation to the methodology used. The objective of this evaluation is to gain feedback on the different aspects of the methodology and activity developed in order to introduce the corresponding improvements in the teaching/learning method. To do this, surveys are carried out among all participating students (preCOVID and postCOVID), the results of which are analyzed and discussed in the following sections. 


\section{Methodology}

\subsection{Phase 1: pre-COVID-19 Sample, Application of Active Methodologies in Face-to-Face Format}

Phase 1 took place, prior to the appearance of the COVID-19 pandemic, between October and December 2019 at the Faculty of Economics and Business (Gipuzkoa campus) of the University of the Basque Country (UPV/EHU) among first- and third-year students in the Degree course of Business Administration and Management. The main objective of the study was to involve students more actively in their learning by combining the use of teaching methodologies and tools (such as the use of real business case studies). To carry out the activity, for each subject of the program, one or more topics were selected that lent themselves well to self-learning because of the level of complexity or practical applicability of the topic content. A secondary objective of the study was to gather the impressions of the students regarding the use of active methodologies for the teaching-learning process and, specifically, to measure motivation, involvement, and other related aspects regarding the use of a smartphone-based tool.

The study was carried out for seven different student groups in two subjects and courses and in two different languages, as can be seen in Table 2.

Table 2. General information about the experience.

\begin{tabular}{ccc}
\hline Date & Subject and Course & Language/Group \\
\hline October to & Business Economics: Introduction (1st year) & Basque/4 groups Spanish/3 groups \\
December 2019 & Strategic Direction: Company Policy (3rd year) & \\
\hline
\end{tabular}

Source: compiled by the authors.

A questionnaire was given to students who had participated in the study in order for them to express their opinions. The questionnaire was structured in 4 blocks: General assessment of the Socrative tool; suitability of its use in the teaching-learning process; assessment of the flipped classroom methodology; and finally, identification data (age, course, expected grade in the subject, sex, and subject). Each block was made up of a series of statements for which students could rate their responses using a 5-point Likert scale. The number of valid questionnaires obtained, and their distribution, can be seen in Table 3 .

Table 3. Information from samples 1 and 2.

\begin{tabular}{ccccc}
\hline & & \multicolumn{2}{c}{ Surveys Carried Out } \\
\hline Subjects & Course & Language & Pre-COVID19 & Post-COVID19 \\
Business Economics: Introduction & 1 & Spanish & 46 & 32 \\
& & Basque & 68 & 37 \\
Strategic Direction: Company Policy & 3 & Spanish & 19 & 21 \\
& & Basque & 37 & 21 \\
& & & 170 & 111 \\
\hline
\end{tabular}

Source: compiled by the authors.

\subsection{Phase 2: Post-COVID-19 Sample, Assessment of Active Methodologies for Their Application in Contexts of} Social Distancing

The second phase took place in the same context, with the same groups and subjects as those carried out in the first phase. However, following the period of confinement, the objective was to assess the students' response to the greater use of active methodologies in the context of social distancing. The data were collected between June and July 2020.

This time, to benefit from the students' previous knowledge of the described methodologies and their recent experience as students during the COVID-19 pandemic, the assessment focused on the students' response to the effectiveness of this type of methodology as a tool for teaching and evaluation. 
Given the difficulty of obtaining a sufficient sample in a non-face-to-face context, a short questionnaire was designed, consisting of only two blocks. Firstly, students were asked 5 questions relating to their satisfaction in the context of COVID-19. They were asked about their satisfaction with the teaching staff, the methodologies used, and their own performance.

Secondly, they were asked four questions related to the role of active methodologies in the flipped classroom, both in the current context and in a possible future scenario of a resurgence of COVID-19.

\subsection{Characteristics of the Sample and Data Analysis}

In the first phase, 170 valid answers were obtained and, in the second phase, 111 answers. Tables 3 and 4 show general information about the samples obtained.

Table 4. Demographic characteristics from samples 1 and 2.

\begin{tabular}{cccc}
\hline Indicator & Answer & Pre-COVID19 & Post-COVID19 \\
\hline Gender & Female & $53.53 \%$ & $66.67 \%$ \\
\hline Course & Male & $46.47 \%$ & $33.33 \%$ \\
\hline \multirow{2}{*}{ Language } & Spanish & $65.29 \%$ & $62.16 \%$ \\
\hline & Basque & $34.24 \%$ & $37.84 \%$ \\
\hline & & $61.76 \%$ & $47.75 \%$ \\
\hline
\end{tabular}

Source: Compiled by the authors.

In order to check the characteristics of the questionnaire, a reliability and validity analysis of the scales used was carried out. For this, as well as for the subsequent analysis of results, RCommander (Rcmdr) was used. Rcmdr is a statistical software of the R programming language and its environment for statistical analysis.

The analysis of the reliability of the scales was carried out using Cronbach's $\alpha$ Coefficient [30]. By means of this coefficient, internal consistency is measured, that is, the degree to which the scale items are correlated with each other. If the items are highly correlated, it suggests that they measure a common variable. The acceptable values for this coefficient are $\alpha \geq 0.7$ [31] and $\alpha \geq 0.8$ [32], and values higher than 0.9 may be indicating the existence of redundant items [33] Furthermore, the reliability is considered as acceptable when it does not fall below 0.5-0.6 [34].

In view of what is stated in Tables 5 and 6 , with the acceptable values for this coefficient being $\alpha \geq 0.5$ or $\alpha \geq 0.6$, the reliability or internal consistency of the scales is contrasted in all cases except for the case of Rating of the Socrative Tool. This basically means that the proposed indicators measure very different aspects of the tool, which are not necessarily related to each other.

In addition to the reliability analysis, it is important to assess the validity of the questionnaire. Validity is the degree to which an instrument measures the concept under study [35], and there are different types: Content validity, validity, convergent, discriminant validity, and nomological validity [36]. In this case, in view of the analysis to be carried out, the content validity of the questionnaire used is reinforced by referring to the use of previous studies on the same subject in the literature analysis. For example, the orientation of the practice used is consistent with the adaptation of the ARCS (Attention, Relevance, Confidence, and Satisfaction) model applied by Asiksoy and Ozdamli [37].

Given the characteristics of the questionnaires and the types of data obtained (ordinal), analysis of these is done in two ways. First, the frequencies of the responses obtained in the items asked in both phases of the study are presented. The objective in both phases was different, so a good part of the items was renewed. However, one question remained unchanged in both samples. This is 
an item that measures the opinion regarding whether the flipped classroom methodology should have more presence in the teaching-learning processes i.e., the general opinion of the students about the acceptance of the methodology. Thus, the results obtained before and after the pandemic can be compared using a Mann-Whitney-Wilcoxon test (after verifying the absence of normality).

Table 5. Reliability of scales, prior to COVID-19.

\begin{tabular}{cl}
\hline Indicator & Alpha \\
\hline Rating of the Socrative Tool & 0.3175 \\
\hline Attractive for learning & 0.2309 \\
\hline Helps identify learning difficulties & 0.1119 \\
\hline Helps achieve learning objectives & 0.6423 \\
\hline Suitability of the use of the Socrative tool & 0.6746 \\
\hline Positive assessment of the tool & 0.5598 \\
\hline Valid tool to achieve qualification & 0.7989 \\
\hline Should be used in more subjects & 0.3477 \\
\hline Assessment of the Flipped classroom methodology & 0.8994 \\
\hline Attractive learning methodology & 0.8635 \\
\hline Helps internalise content better & 0.8797 \\
\hline Increased interest in the subject & 0.8650 \\
\hline This methodology should be used more frequently & 0.8726 \\
\hline
\end{tabular}

Source: compiled by the authors using Rcmdr.

Table 6. Reliability of scales, post-COVID-19.

\begin{tabular}{|c|c|}
\hline Indicator & Alpha \\
\hline Assessment of the performance of students and teachers during isolation & 0.8073 \\
\hline The teachers' adaptation was good & 0.7166 \\
\hline The teachers made a significant effort & 0.7314 \\
\hline The students' adaptation was good & 0.8006 \\
\hline Active participation & 0.8554 \\
\hline Satisfaction with the methodologies used during the pandemic & 0.7134 \\
\hline $\begin{array}{c}\text { Assessment of students regarding the validity of active methodologies in } \\
\text { the context of a pandemic }\end{array}$ & 0.6279 \\
\hline $\begin{array}{l}\text { If a similar situation were to occur, the teaching staff should implement } \\
\text { active methodologies, reducing the onus of lectures }\end{array}$ & 0.5684 \\
\hline $\begin{array}{l}\text { Whether there is a return to confinement or not, in the future there should } \\
\text { be more active methodologies that require less attendance }\end{array}$ & 0.4411 \\
\hline $\begin{array}{l}\text { Teachers should opt more for teaching methodologies in which students } \\
\text { work on their own, and group sessions should be used to review case } \\
\text { studies or answer common queries, etc. }\end{array}$ & 0.5511 \\
\hline $\begin{array}{l}\text { In a pandemic context, the evaluation system should give more weight to } \\
\text { continuous evaluation through active learning methodologies }\end{array}$ & 0.6306 \\
\hline
\end{tabular}

Source: compiled by the authors using Rcmdr.

\section{Results}

As indicated, 281 valid questionnaires were collated, 170 before COVID-19 and 111 after the first period of confinement. Table 7 shows the main descriptive results obtained through the study, prior to COVID-19. 
Table 7. Descriptive results of the study prior to COVID-19.

\begin{tabular}{|c|c|c|c|c|c|}
\hline Indicator & 1 & 2 & 3 & 4 & 5 \\
\hline & $\begin{array}{c}\text { Strong } \\
\text { disagree }\end{array}$ & Disagree & $\begin{array}{l}\text { Neither agree } \\
\text { nor disagree }\end{array}$ & Agree & $\begin{array}{c}\text { Strong } \\
\text { agree }\end{array}$ \\
\hline \multicolumn{6}{|c|}{ Rating of the Socrative Tool (\%) } \\
\hline Attractive for learning & 1.2 & 2.4 & 16.7 & 32.7 & 47.0 \\
\hline Helps identify learning difficulties & 0.0 & 4.8 & 23.2 & 44.6 & 27.4 \\
\hline Helps achieve learning objectives & 0.0 & 3.6 & 23.2 & 49.4 & 23.8 \\
\hline \multicolumn{6}{|c|}{ Suitability of use of the Socrative tool (\%) } \\
\hline Positive assessment of the tool & 0.6 & 1.8 & 8.3 & 31.4 & 58.0 \\
\hline Valid tool to achieve qualification & 3.6 & 13.6 & 32 & 34.9 & 16.0 \\
\hline Should be used in more subjects & 1.2 & 2.4 & 17.3 & 26.2 & 53.0 \\
\hline \multicolumn{6}{|c|}{ Assessment of the Flipped classroom methodology (\%) } \\
\hline Attractive learning methodology & 1.8 & 6.6 & 26.3 & 46.1 & 19.2 \\
\hline Helps internalise content better & 1.8 & 7.2 & 21.0 & 50.3 & 19.8 \\
\hline Increased interest in the subject & 3.0 & 9.6 & 33.1 & 45.2 & 9.0 \\
\hline $\begin{array}{l}\text { Flipped classroom methodology } \\
\text { should be used more frequently }\end{array}$ & 3.0 & 7.8 & 28.3 & 39.2 & 21.7 \\
\hline $\begin{array}{l}\text { Percentage of the subject that } \\
\text { should be covered using this } \\
\text { methodology }\end{array}$ & $\begin{array}{l}0-20 \% \\
12.2 \%\end{array}$ & $\begin{array}{c}21-40 \% \\
26.3 \%\end{array}$ & $\begin{array}{c}41-60 \% \\
25 \%\end{array}$ & $\begin{array}{l}61-80 \\
26.9 \%\end{array}$ & $\begin{array}{c}81-100 \\
9.6 \%\end{array}$ \\
\hline
\end{tabular}

Source: compiled by the authors.

As can be seen in Table 7, the responses related to the Socrative tool and those related to the flipped classroom methodology are quite positive. In particular, the responses regarding the Socrative tool are very positive, both in terms of its general assessment and its usability and usefulness.

However, the greatest concerns are regarding its ability to serve as an assessment tool. The results show that a significant percentage of the students share this concern. Nevertheless, more than half of the students consider that this tool can be used for grading a student's performance in a subject.

Regarding the flipped classroom methodology, the results are similar to the trend observed for the Socrative questions. Most of the students give a positive evaluation of this methodology, and more than $80 \%$ believe that it should be used to study a greater part of the subject content (more than $21 \%$ of its content).

Regarding phase 2, Table 8 summarizes the information obtained on completion of the study following the COVID-19 pandemic.

The first block of questions attempts to measure the general perception of the students regarding the first critical months of the pandemic and their experience with online teaching (in general). Overall, the analysis of each item shows that the students are generally satisfied with their own performance, the effort made by the teaching staff and their own participation (scoring 4 out of 5). Opinion is a little more ambivalent on the adaptability of teachers and the methodologies used (scoring 3 out of 5 ).

Regarding the validity of active methodologies related to the flipped classroom approach, it is clear that students, in general, value them in a very positive way $(35.8 \%$ agree and $49.5 \%$ strongly agree on expanding its use; and less than $3 \%$ have a negative opinion of it). The opinion regarding a possible repetition of an emergency lockdown is clear: students believe that active methodologies could play a greater role in the evaluation of the subjects and should be given preference above lectures. However, it seems that this opinion is less emphatic if the context is not that of a pandemic. Therefore, this reinforces the idea of the adaptation of this type of methodology to contexts of isolation. 
Nevertheless, it is clear that a significant effort is required to explain and correctly apply the flipped classroom methodology, since the question related to this approach is the worst rated. Possibly, in a context of disenchantment on the part of the students, the idea of preparing the most basic part of the subject on their own is not seen as an attractive option.

Table 8. Descriptive results of the study, post-COVID-19.

\begin{tabular}{|c|c|c|c|c|c|}
\hline Indicator & 1 & 2 & 3 & 4 & 5 \\
\hline & $\begin{array}{l}\text { Strongly } \\
\text { disagree }\end{array}$ & Disagree & $\begin{array}{l}\text { Neither agree } \\
\text { nor disagree }\end{array}$ & Agree & $\begin{array}{l}\text { Strongly } \\
\text { agree }\end{array}$ \\
\hline \multicolumn{6}{|c|}{ Assessment of the performance of students and teachers during isolation (\%) } \\
\hline The teachers' adaptation was good & 3.6 & 19.8 & 35.1 & 31.5 & 9.9 \\
\hline The teachers made a significant effort & 2.7 & 18.9 & 24.3 & 39.6 & 14.4 \\
\hline The students' adaptation was good & 3.6 & 7.2 & 36.9 & 40.5 & 11.7 \\
\hline Active participation & 0.9 & 10.0 & 12.7 & 34.5 & 41.8 \\
\hline $\begin{array}{l}\text { Satisfaction with the methodologies } \\
\text { used during the pandemic }\end{array}$ & 8.1 & 19.8 & 31.5 & 28.8 & 11.7 \\
\hline \multicolumn{6}{|c|}{ Assessment of students regarding the validity of active methodologies in the context of a pandemic (\%) } \\
\hline $\begin{array}{l}\text { Flipped classroom methodology } \\
\text { should be used more frequently }\end{array}$ & 1.8 & 0.9 & 11.9 & 35.8 & 49.5 \\
\hline $\begin{array}{l}\text { Whether there is a return to } \\
\text { confinement or not, in the future there } \\
\text { should be more active methodologies } \\
\text { that require less attendance }\end{array}$ & 12.0 & 10.2 & 19.4 & 26.9 & 31.5 \\
\hline $\begin{array}{l}\text { Teachers should opt more for } \\
\text { teaching methodologies in which } \\
\text { students work on their own, and } \\
\text { group sessions should be used to } \\
\text { review case studies or answer } \\
\text { common queries, etc. }\end{array}$ & 10.0 & 14.5 & 31.8 & 26.4 & 17.3 \\
\hline $\begin{array}{l}\text { In a pandemic context, the evaluation } \\
\text { system should give more weight to } \\
\text { continuous evaluation through active } \\
\text { learning methodologies }\end{array}$ & 2.8 & 1.8 & 14.7 & 23.9 & 56.9 \\
\hline
\end{tabular}

Source: Compiled by the authors.

In the second assessment, in the context of the global health pandemic caused by COVID-19, we want to see if this has led to changes in the perception of students, giving a better or worse opinion of the implementation of this type of tool.

As explained in the methodology section, the general question about the acceptance of the flipped classroom methodology is the only item that has remained constant in both questionnaires. To establish whether there are significant differences in opinions before and after the onset of the pandemic, a contrast of significant differences is carried out in their mean values.

First, an analysis to see whether the variables for the different samples have a normal distribution is done by means of the Shapiro-Wilk normality test. The Shapiro-Wilk test is used to contrast the normality of a dataset. Table 9 shows the results of the Shapiro-Wilk normality test for the two variables.

The probability value $(p)$ of acceptance of the null hypothesis (normality in the data) is much less than 0.05 , therefore it is rejected. In other words, it can be concluded that the distribution of the data for that item is not normal. 
Table 9. Shapiro-Wilk normality test.

\begin{tabular}{ccc}
\hline $\begin{array}{l}\text { Flipped Classroom Methodology } \\
\text { Should be Used More Frequently }\end{array}$ & W & $\boldsymbol{p}$-Value \\
\hline PRE-COVID19 & 0.88105 & $3.066 \times 10^{-10}$ \\
\hline POST-COVID19 & 0.75127 & $2.661 \times 10^{-12}$ \\
\hline
\end{tabular}

Source: Compiled by the authors using Rcmdr.

Given that the samples for the variables do not follow a normal distribution, a Mann-Whitney-Wilcoxon non-parametric test is performed to test for the existence of significant differences in the mean values in the variable analyzed.

The probability value $(p)$ is well below the 0.05 level, so the null hypothesis of equality of means is rejected (Table 10). That is, it can be concluded that there are significant differences. In other words, and analyzing the frequency tables in a complementary manner, it seems that after the onset of the pandemic the students value the use of active methodologies such as the flipped classroom even more, and their opinion regarding its capacity to serve as a tool for evaluation is higher.

Table 10. Mann-Whitney-Wilcoxon test.

\begin{tabular}{lcc}
\hline $\begin{array}{l}\text { Flipped Classroom Methodology } \\
\text { Should be Used More Frequently }\end{array}$ & W- $U$ & $p$-Value \\
\hline PRE-COVID19/POST COVID19 & 5743.5 & 0.00000006813 \\
\hline \multicolumn{4}{c}{ Source: Compiled by the authors using Rcmdr. }
\end{tabular}

We also looked more closely at whether there are significant differences between the mean values of first- and third-year students, by analyzing whether opinions about the methodology varied throughout the grade. Table 11 shows the results of the test when comparing both groups at both times, before and after the onset of the pandemic.

Table 11. Mann-Whitney-Wilcoxon test.

\begin{tabular}{cccc}
\hline $\begin{array}{l}\text { Flipped Classroom Methodology } \\
\text { Should be Used More Frequently }\end{array}$ & Sample & W-U & $\boldsymbol{p}$-Value \\
\hline \multirow{2}{*}{ 1st versus 3rd course } & PRE-COVID19 & 3770.5 & 0.002191 \\
\cline { 2 - 4 } & POST-COVID19 & 1419.5 & 0.8638 \\
\hline
\end{tabular}

Source: Compiled by the authors using Rcmdr.

The probability value $(\mathrm{p})$ is less than 0.05 in the sample prior to the onset of the pandemic, so the null hypothesis is rejected. In other words, it can be concluded that there are significant differences between the values of the first- and third-year students. However, in the second phase sample, the probability value $(\mathrm{p})$ is much higher than 0.05 , so the null hypothesis is accepted. It can be concluded that there are no significant differences between the opinions of people in the first and third years.

In order to understand these results, Table 12 shows the distribution of the responses offered by both groups of students in the two phases.

It is clear that the responses in the sample prior to the pandemic are different between students of both courses. Opinions regarding the methodology were more favorable among first-year students. However, after the appearance of COVID-19, opinions clearly evolved in a favorable direction in both groups, even reaching the same level until no significant differences were shown. Totally favorable responses to the greater use of active methodologies went from $28.35 \%$ in the first year and $7.5 \%$ in the third to $51.5 \%$ and $46.3 \%$, respectively. The figures speak for themselves in demonstrating the change in opinion of the students. 
Table 12. Distribution of responses according to course and sampling phase.

\begin{tabular}{cccccccc}
\hline \multicolumn{7}{c}{ Flipped Classroom Methodology Should be Used More Frequently } & \\
\hline & & $\mathbf{1}$ & $\mathbf{2}$ & $\mathbf{3}$ & $\mathbf{4}$ & $\mathbf{5}$ \\
\cline { 3 - 7 } & & $\begin{array}{c}\text { Strongly } \\
\text { disagree }\end{array}$ & Disagree & $\begin{array}{c}\text { Neither agree nor } \\
\text { disagree }\end{array}$ & Agree & $\begin{array}{c}\text { Strongly } \\
\text { agree }\end{array}$ \\
\hline \multirow{2}{*}{ PRE-COVID19 } & 1st course & 2.7 & 5.3 & 25.7 & 38.1 & 28.3 \\
& 3rd course & 3.8 & 13.2 & 34.0 & 41.5 & 7.5 \\
\hline \multirow{2}{*}{ POST-COVID19 } & 1st course & 2.9 & 1.5 & 11.8 & 32.4 & 51.5 \\
& 3rd course & 0.0 & 0.0 & 12.2 & 41.5 & 46.3 \\
\hline
\end{tabular}

Source: Compiled by the authors using Rcmdr.

\section{Discussion and Recommendations}

The general perception of the methodology (flipped classroom) and the specific tool (Socrative) is positive. The score for most of the items is 4 out of 5 , although it is worth highlighting the existence of a significant percentage of students who give a score of 3 , that is, showing a certain indifference or a lack of commitment to these types of active methodologies. The existence of groups with a passive attitude or even contrary to this type of methodology was demonstrated in a literature review carried out by Ward, Knowlton, and Laney [38]. According to these authors, the greater effort needed and the greater investment of time required for active methodologies encourages students to opt for "passive methodologies". Most of the studies found in the literature show similar results. For example, both the work of Wash [27] and that of Kaya and Balta [39] reveal especially positive evaluations regarding class participation, the feedback received, and regarding mental challenge.

The literature review regarding the flipped classroom and active methodologies in higher education is classified into studies from the point of view of teachers and techniques used [25], those that try to measure perceptions of the teaching-learning process, and academic results achieved [38]. There are even studies that show that the use of the Socrative tool significantly improves the results obtained. Along the same lines, the study by Dakka [40] showed that the use of the Socrative tool significantly improved the results obtained. The work of Sein-Echaluce, Fidalgo, and García [19] also clearly shows a better performance in the group of experimental students compared to the control group, that is, beyond perceptions, improvements are also detected in the impact on learning and retention of it. In the results obtained in this study, a large part of the students perceive improvements related to the internalization of learning objectives and the assimilation of content (almost three out of foir students rated these questions 4 or 5 out of 5 before the pandemic).

Small differences aside, practically all the studies carried out in recent years show similar results, with very positive evaluations regarding all variables in most cases [25,26,41-44].

In general, students tend to consider that this methodology promotes the understanding of key concepts and their mastery of the subject, thereby improving their learning [18,45-48]. It is a methodology that is valued above traditional classes [27], although in some cases, a proportion of the students still prefer the traditional methodology over the active methodologies of this type [45]. The results obtained are consistent with this vision, that is, a fairly favorable attitude is detected regarding the tools used, but there are certain limitations, especially regarding their ability to evaluate.

The second part of the data analysis attempted to understand the impact of COVID-19 on opinions about active methodologies and digital tools. Comparing both samples, it can be seen that, in a health emergency context, the opinions are notably more favorable than before the pandemic.

Despite the fact that the phenomenon of the COVID-19 pandemic is extremely recent, there are already several studies that support the suitability of active methodologies, and specifically the flipped classroom, as tools to be implemented in contexts of social isolation $[2,4-6,49,50]$. The data show that these opinions are also shared in the groups analyzed, with support for this type of active methodology increasing greatly after the appearance of the pandemic. 
Given the positive results regarding the methodology, as well as its assessment as a way of continuing learning in the context of a pandemic, we propose the model be adapted to use in face-to-face classroom settings, albeit in a controlled way [51].

\section{Conclusions}

The rapid spread of COVID-19 has led to a change in patterns of social behavior, worldwide. This situation forced society to adopt new habits and behaviors. Consequently, many educational institutions, including those of higher education, moved quickly to adjust their teaching approaches and suspend face-to-face classes. Universities had to adapt to this situation by restructuring their teaching methods by teaching classes online, trying to ensure the continuity and quality of teaching.

In this context, the inverted classroom offers an approach to help meet the needs arising from a global health emergency. It is a valuable methodology for supporting individual development while using digital tools that guarantee social distancing and ensure teachers and student remain in touch.

The conclusions reached after analysis of this experience are based on a triangulation of sources: Literature review, student data analysis, and teacher experience in applying the flipped classroom as an active methodology.

As we have contrasted in the discussion section, there is a certain consensus regarding the validity of the flipped classroom when it comes to generating improvements in the interest, effort, and participation of students. It is true, however, that several cases reflect a certain preference on the part of the students for traditional methodologies that require less effort throughout the course.

Nevertheless, the data analysis has allowed us to draw some pertinent conclusions. Despite the majority of opinions received being favorable, there are also a significant number of students who are not enthusiastic about active methodologies. In addition, there appears to be some concerns about using tools related to these methodologies as a way of evaluation, and so their application should be implemented with the relevant assurances.

Lastly, the experience developed identifies a series of aspects of learning and improvement that teachers should consider. On the one hand, more specific material should be created for the planned activities. A video presentation is very useful to reinforce the presentation of the activity and provides greater flexibility and the possibility of remote realization, especially useful in times of pandemic. On the other hand, the exercises or cases to be solved must be designed bearing in mind their application through this type of methodology from the outset. If not, past experiences have shown us that it is more difficult to fit the work with the proposed phases. Time must be properly managed, distinguishing clearly between tasks that students can/must do outside the classroom space (face-to-face or virtual) and those that require face-to-face time in the classroom (group feedback activities or complex tasks at a cognitive level). From personal experience, we recommend starting gradually, setting more ambitious targets as the teachers themselves gain experience and mastery of the selected methodology.

Returning to the main objective of the study as stated in the introduction, the results of the experience carried out affirm that active methodologies based on the flipped classroom can be very useful in the context of a COVID-19 pandemic. The pandemic represents a historic milestone in the evolution of higher education and virtual teaching. The challenge that normal academic development faced has been met with the development of virtual teaching. As reiterated by the students themselves, traditional teaching methodologies based on face-to-face interaction are unworkable for contexts such as the current one. Therefore, to finish, we summarize in Table 13 the main recommendations for the application of the flipped classroom methodology in a virtual environment.

In summary, the potential benefits of active methodologies and, specifically, the flipped classroom can be exploited in an online environment, and this is perceived by both the students and the teachers involved in the experience. However, the challenges generated by the pandemic are significant, and responsibility must be demanded of the educational authorities on three fronts, mainly: (1) Identification of students with economic, social, or health difficulties, and provision 
of means and facilities for them; (2) development of advanced technological tools with sufficient potential (own or acquired); (3) provision of material resources and training focused on active methodologies for all teaching staff.

The main limitation of this study stems from the instability of the current world health situation, with the uncertainty that this brings. Because of the circumstances, collection of information for the study had to be done remotely. Thus, the response rate was somewhat lower, and offering any face-to-face guidance to the person completing the questionnaire was impossible. Nevertheless, a sufficient number of completed questionnaires was collated to make the study viable.

Table 13. Final recommendations based on the four pillars of flipped learning.

\begin{tabular}{|c|c|c|c|}
\hline Pillar FLIP & Benefits Obtained & COVID-19 Risks & $\begin{array}{l}\text { Recommendation in the Context of } \\
\text { COVID-19 }\end{array}$ \\
\hline Flexible environment & $\begin{array}{l}\text { Possibility of adapting to } \\
\text { different needs and pace of } \\
\text { learning }\end{array}$ & $\begin{array}{l}\text { Not all students have the } \\
\text { necessary technological } \\
\text { means or a stable family } \\
\text { environment }\end{array}$ & $\begin{array}{l}\text { Online spaces adapted to different needs and } \\
\text { personal situations. } \\
\text { Tools that allow different pace/time to study. } \\
\text { Special effort to detect cases that need } \\
\text { individual response }\end{array}$ \\
\hline Learning culture & $\begin{array}{l}\text { Active participation of students. } \\
\text { Protagonism passes from the } \\
\text { teacher to the work of the } \\
\text { students. }\end{array}$ & $\begin{array}{l}\text { Restrictions of face-to-face } \\
\text { group work. } \\
\text { Risk of loss of control over } \\
\text { students who do not } \\
\text { follow the minimum } \\
\text { recommended pace. }\end{array}$ & $\begin{array}{l}\text { Search for technological tools that promote } \\
\text { remote group work (wiki, forums, online } \\
\text { workshops, co-evaluation). } \\
\text { Continuous feedback, identification of "off the } \\
\text { hook" cases. } \\
\text { Alternative routes for students with personal } \\
\text { difficulties (inclusion via group work and peer } \\
\text { feedback). }\end{array}$ \\
\hline Intentional content & $\begin{array}{l}\text { Potential of materials developed } \\
\text { specifically for the proposed } \\
\text { learning objectives. } \\
\text { Optimization of time to develop } \\
\text { active learning strategies. } \\
\text { Continuous feedback identifies } \\
\text { areas where learning } \\
\text { reinforcement is required. }\end{array}$ & $\begin{array}{l}\text { Students not focused due } \\
\text { to distance (physical and } \\
\text { psychological). } \\
\text { Impossibility of working } \\
\text { the same content in the } \\
\text { same way as in a normal } \\
\text { context. }\end{array}$ & $\begin{array}{c}\text { Clear objectives, effort to develop specific } \\
\text { materials for the methodology used. } \\
\text { Short and clear videos transmitting basic } \\
\text { information about the activity and the expected } \\
\text { objectives. } \\
\text { Case studies adapted to the learning process. }\end{array}$ \\
\hline Professional educator & $\begin{array}{l}\text { Teacher more involved, with an } \\
\text { active role in continuous } \\
\text { feedback. } \\
\text { Adaptability and flexibility. }\end{array}$ & $\begin{array}{c}\text { Complex situation. } \\
\text { Difficulty managing large } \\
\text { groups. } \\
\text { Limitations regarding } \\
\text { technological equipment } \\
\text { and online tools available. }\end{array}$ & $\begin{array}{c}\text { Flexibility. } \\
\text { Setting manageable targets (targets that are too } \\
\text { ambitious can cause loss of control and } \\
\text { frustration). } \\
\text { Teamwork, sharing experiences. }\end{array}$ \\
\hline
\end{tabular}

Source: Flipped Learning Network, 2019.

Author Contributions: Conceptualization, J.I.-O.; Methodology, J.I.-O. and J.M.-A.; Software, J.M.-A.; Validation, J.M.-A.; Formal Analysis, J.I.-O.; Investigation, J.I.-O. and J.M.-A.; Resources, J.I.-O. and J.M.-A.; Data Curation, J.I.-O. and J.M.-A.; Writing-Original Draft Preparation, J.I.-O.; Writing-Review \& Editing, J.I.-O. and J.M.-A.; Visualization, J.I.-O. and J.M.-A.; Supervision, J.I.-O.; Project Administration, J.I.-O.; Funding Acquisition, J.I.-O. and J.M.-A. All authors have read and agreed to the published version of the manuscript.

Funding: This research was funded by Basque Government, grant number IT-1327 and by University of the Basque Country (UPV/EHU), grant number PIE-HBP-111.

Conflicts of Interest: The authors declare no conflict of interest.

\section{References}

1. WHO. Coronavirus Disease (COVID-19) Pandemic. 2020. Available online: https://www.who.int/ emergencies/diseases/novel-coronavirus-2019 (accessed on 12 November 2020).

2. Bozkurt, A.; Sharma, R.C. Emergency remote teaching in a time of global crisis due to CoronaVirus pandemic. Asian J. Distance Educ. 2020, 15, 1-6.

3. Walensky, R.P.; Del Rio, C. From mitigation to containment of the COVID-19 pandemic: Putting the SARS-CoV-2 genie back in the bottle. JAMA 2020, in press. [CrossRef] [PubMed] 
4. Chick, R.C.; Clifton, G.T.; Peace, K.M.; Propper, B.W.; Hale, D.F.; Alseidi, A.A.; Vreeland, T.J. Using technology to maintain the education of residents during the COVID-19 pandemic. J. Surg. Educ. 2020, 77, 729-732. [CrossRef] [PubMed]

5. Hossain Khan, M.S.; Abdou, B.O. Flipped classroom: How institutions of higher education (HEIs) of Bangladesh could move forward during Covid-19 pandemic. Soc. Sci. Humanit. Open 2020. Available online: https://papers.ssrn.com/sol3/papers.cfm?abstract_id=3615400 (accessed on 12 November 2020).

6. Leigh, J.; Vasilica, C.; Dron, R.; Gawthorpe, D.; Burns, E.; Kennedy, S.; Warburton, T.; Croughan, C. Redefining undergraduate nurse teaching during the coronavirus pandemic: Use of digital technologies. Br. J. Nurs. 2020, 29, 566-569. [CrossRef] [PubMed]

7. Fortanet van Assendelft de Coningh, C.A.; González Díaz, C.; Mira Pastor, E.; López Ramón, J.A. Aprendizaje Cooperativo y Flipped Classroom. Ensayos y Resultados de la Metodología Docente; Universidad de Alicante: Alicante, Spain, 2013.

8. CRUE. Propuestas Metodológicas para la Renovación de las Metodologías Educativas; MEC: Madrid, Spain, 2006.

9. Fernández March, A. Metodologías activas para la formación de competencias. Educ. Siglo XXI 2006, 24, 35-56.

10. Tejedor, S.; Cervi, L.; Pérez-Escoda, A.; Jumbo, F.T. Digital literacy and higher education during COVID-19 lockdown: Spain, Italy and Ecuador. Publications 2020, 8, 48. [CrossRef]

11. Tejedor, S.; Cervi, L.; Tusa, F.; Parola, A. Educación en tiempos de pandemia: Reflexiones de alumnos y profesores sobre la enseñanza virtual universitaria en España, Italia y Ecuador. Rev. Lat. Comun. Soc. 2020, 78, 1-21.

12. Cervi, L.; Pérez Tornero, J.M.; Tejedor, S. The challenge of teaching mobile journalism through MOOCs: A case study. Sustainability 2020, 12, 5307. [CrossRef]

13. Segura-Robles, A.; Parra-González, M.E.; Gallardo-Vigil, Á. Bibliometric and collaborative network analysis on active methdologies in education. J. New Approaches Educ. Res. 2020, 9, 259-274. [CrossRef]

14. Felder, R.; Brent, R. Active learning: An introduction. ASQ High. Educ. Brief 2009, 2. Available online: http: //www4.ncsu.edu/unity/lockers/users/f/felder/public/Papers/ALpaper(ASQ).pdf (accessed on 26 November 2020).

15. Burganova, R.; Abdullina, S.; Tuyakova, A. Improving the quality of education through student-centered education. Ser. Soc. Hum. Sci. 2018, 6, 102-104. [CrossRef]

16. Bai, S.; Hew, K.F.; Huang, B. Does gamification improve student learning outcome? Evidence from a meta-analysis and synthesis of qualitative data in educational contexts. Educ. Res. Rev. 2020, 30, 100322. [CrossRef]

17. Flipped Learning Network. What is Flipped Learning? 2020. Available online: https://flippedlearning.org (accessed on 12 November 2020).

18. Sánchez Rodríguez, J.; Ruiz Palmero, J.; Sánchez Vega, E. Flipped classroom. Claves para su puesta en práctica. Edmetic Rev. Educ. Mediat. TIC 2017, 6, 336-358. [CrossRef]

19. Sein-Echaluce Lacleta, M.L.; Fidalgo Blanco, A.; García Peñalvo, F. Metodología de enseñanza inversa apoyada en b-learning y gestión del conocimiento. In Proceedings of the III Congreso Internacional Sobre Aprendizaje, Innovación y Competitividad, Madrid, Spain, 14-16 October 2015.

20. Fadini, K.; Finardi, K.R. Affordances of web 2.0 interfaces for the teaching/learning of L2 in the flipped classroom. In Proceedings of the International Conference of Education, Research and Innovation, Seville, Spain, 18-20 November 2015; pp. 1052-1058.

21. Marqués, M. Qué hay detrás de la clase al revés (flipped classroom). In Proceedings of the XXII JENUI, Almería, Spain, 6-8 July 2016.

22. Roach, T. Student perceptions toward flipped learning. New methods to increase interaction and active learning in economics. Int. Rev. Econ. Educ. 2014, 17, 74-84. [CrossRef]

23. Flipped Learning Network. Definition of Flipped Learning. 2019. Available online: https://flippedlearning. org/definition-of-flipped-learning/ (accessed on 12 November 2020).

24. Awedh, M.; Mueen, A.; Zafar, B.; Manzoor, U. Using socrative and smartphones for the support of collaborative learning. Int. J. Integr. Technol. Educ. 2014, 3, 17-24. [CrossRef]

25. De Lozier, S.; Rhodes, M.G. Flipped classrooms: A review of key ideas and recommendations for practice. Educ. Psich. Rev. 2016, 29, 141-151.

26. Méndez Coca, D.; Slisko, J. Software socrative and smartphones as tools for implementation of basic processes of active physics learning in classroom: An initial feasibility study with prospective teachers. Eur. J. Phys. Educ. 2013, 3, 17-24.

27. Wash, P. Taking advantage of mobile devices: Using socrative in the classroom. J. Teach. Learn. Technol. 2014, 3, 99-101. [CrossRef] 
28. Bloom, B.S. Learning for Mastery. Eval. Comment 1968, 1, 1-12.

29. López García, J.C. La Taxonomía de Bloom y sus Actualizaciones. Eduteka. Available online: http: //eduteka.icesi.edu.co/pdfdir/TaxonomiaBloomCuadro.pdf (accessed on 26 November 2020).

30. Cronbach, L.J. Coefficient alpha and the internal structure of tests. Psychometrika 1951, 16, 297-334. [CrossRef]

31. Nunnally, J.C.; Bernstein, I.H. Psychometric Theory, 3rd ed.; McGraw-Hill: New York, NY, USA, 1994.

32. Carmines, E.; Zeller, R. Reliability and Validity Assessment; SAGE: Thousand Oaks, CA, USA, 1979.

33. Nunnally, J.C. Psychometric Theory, 2nd ed.; McGraw-Hill: New York, NY, USA, 1978.

34. Hair, J.F.; Anderson, R.E.; Tatham, R.L.; Black, W.C. Análisis Multivariante, 5th ed.; Prentice Hall: Madrid, Spain, 1999.

35. Bohrnstedt, G.W. Evaluación de la Confiabilidad y Validez en la Medición de Actitudes; Trillas: Mexico DF, Mexico, 1976.

36. Vila, N.; Küster, I.; Aldás, J. Desarrollo y validación de escalas de medida en Marketing. Quad. Treb. 2000, 104, 1-73.

37. Asiksoy, G.; Özdamli, F. Flipped classroom adapted to the ARCS model of motivation and applied to a physiscs course. Eurasia J. Math. Sci. Technol. Educ. 2016, 12, 1589-1603. [CrossRef]

38. Ward, M.; Knowlton, M.C.; Laney, C.W. The flip side of traditional nursing education: A literature review. Nurse Educ. Pract. 2018, 29, 163-171. [CrossRef] [PubMed]

39. Kaya, A.; Balta, N. Taking advantage of technologies: Using the socrative in English language teaching classes. Int. J. Soc. Sci. Educ. Stud. 2016, 2, 4-12.

40. Dakka, S.M. Using socrative to enhance in class student engagement and collaboration. Int. J. Integr. Technol. Educ. 2015, 4, 13-19. [CrossRef]

41. Altaany, F.H.; Alsoudani, K.A. Impact of using socrative for student in Irbid National University. In Proceedings of the 3rd Global Summit on Education GSE, Kuala Lumpur, Malaysia, 9-10 March 2015.

42. Dervan, P. Enhancing in-class student engagement using socrative (an online student response system): A report. All Irel. J. Teach. Learn. High. Educ. 2014, 6, 1801-1813.

43. Hernández Nanclares, N.; Pérez Rodríguez, M. Students' satisfaction with a blend instructional design: The potential of "flipped classroom" in higher education. J. Interact. Media Educ. 2015, 1, 1-12.

44. Parra-González, M.E.; López Belmonte, J.; Segura-Robles, A.; Fuentes Cabrera, A. Active and emerging methodologies for ubiquitous education: Potentials of flipped learning. Sustainability 2020, 12, 602. [CrossRef]

45. Kong, S.C. Developing information literacy and critical thinking skills through domain knowledge learning in digital classrooms: An experience of practicing flipped classroom strategy. Comput. Educ. 2014, 78, 160-173. [CrossRef]

46. Fernández, M.; Godoy Guglielmone, M.V.; Mariño, S.I.; Barrios, W. ¿Invirtiendo la clase o invirtiendo en la clase? Enseñanza de tecnología para la producción multimedia mediante Aula invertida. In Proceedings of the XXIII Congreso Argentino de Ciencias de la Computación, Buenos Aires, Argentina, 9-13 October 2017.

47. García-Estupiñán, S.B.; Castro, N.C.; Mera, F. Aplicación del flipped classroom en la carrera de economía agrícola: Una experiencia práctica. Rev. Cient. Cienc. Tecnol. 2019, 19, 75-88.

48. Platero, M.; Tejeiro, M.R.; Reis, F. La aplicación de flipped classroom en el curso de dirección estratégica. In Proceedings of the XII Jornadas Internacionales de Innovavión Universitaria, Villaviciosa de Odón, Spain, 20-21 July 2015; pp. 119-133.

49. Marques, B. Will virtual teaching continue after the COVID-19 Pandemic? Acta Med. Port. 2020, 33, 440-448.

50. Pacheco, L.F.; Noll, M.; Rodrigues, C. Challenges in teaching human anatomy to students with intellectual disabilities during the Covid-19 pandemic. Anat. Sci. Educ. 2020, in press. [CrossRef] [PubMed]

51. Izagirre-Olaizola, J.; Morandeira-Arca, J.; Mitxeo-Grajirena, J.; Mendizabal-Alkorta, A.; Lertxundi-Lertxundi, A. Reinforcing the involvement of students in learning business economics through active methodologies and student response systems. J. Manag. Bus. Educ. 2020, 3, 29-46. [CrossRef]

Publisher's Note: MDPI stays neutral with regard to jurisdictional claims in published maps and institutional affiliations. 